\title{
FREQUENCY OF FLU-LIKE SYMPTOMS AND THE CONCERNS ON THE COVID-19 PANDEMIC IN GRADUATE MEDICAL STUDENTS FROM ALL BRAZILIAN REGIONS - A REAL LIFE STUDY
}

Samuel Elias Basualto Dias ${ }^{1, \star}$, Aline Rizzo Borges ${ }^{2}$, João Vitor Ziroldo Lopes ${ }^{3}$, Mirhelen Mendes Abreu, Cleandro Pires Albuquerque $^{5}$, Nafice Costa Araújo ${ }^{6}$, Ana Beatriz Bacchiega ${ }^{7}$, Blanca Bica ${ }^{4}$, Danielle Christinne Soares Egypto Brito ${ }^{8}$, Ângela Luzia Branco Pinto Duarte ${ }^{9}$, Paula Reale Fernandes ${ }^{10}$, Gilda Aparecida Ferreira ${ }^{11}$, Kirla Wagner Poti Gomes ${ }^{12}$, Ana Karla Guedes ${ }^{8}$, Adriana Maria Kakehasi ${ }^{11}$, Bárbara Stadler Kahlow ${ }^{13}$, Evandro Mendes Klumb ${ }^{14}$, Henrique de Ataíde Mariz ${ }^{9}$, Claudia Diniz Lopes Marques ${ }^{9}$, Licia Maria Henrique Mota ${ }^{5}$, Eduardo dos Santos Paiva15, Helena Lucia Alves Pereira', Marcelo Medeiros Pinheiro ${ }^{16}$, José Roberto Provenza ${ }^{17}$, Ana Paula Monteiro Gomides ${ }^{5}$, Edgard Torres Reis-Neto ${ }^{16}$, Emília Inoue Sato ${ }^{16}$, Thelma Skare $^{13}$, Viviane Angelina de Souza ${ }^{10}$, Maycoln Leôni Martins Teodoro ${ }^{11}$, Lilian David de Azevedo Valadares ${ }^{9}$, Valeria Valim ${ }^{18}$, Gecilmara Salviato Pileggi7, Gabriela Araújo Munhoz ${ }^{19}$, Débora Cerqueira Calderaro ${ }^{11}$, Sandra Lucia Euzébio Ribeiro ${ }^{1}$

1.Universidade Federal do Amazonas, Manaus (AM), Brazil. 2.Centro Universitário de Brasília, Brasília (DF), Brazil. 3.Universidade de São Paulo, São Paulo (SP), Brazil. 4.Universidade Federal do Rio de Janeiro, Rio de Janeiro (RJ), Brazil. 5.Universidade de Brasília, Brasília (DF), Brazil. 6. Hospital do Servidor Público Estadual de São Paulo, São Paulo (SP), Brazil. 7.Faculdade de Medicina de Barretos, Barretos (SP), Brazil. 8.Universidade Federal da Paraíba, João Pessoa (PB), Brazil. 9.Universidade Federal de Pernambuco, Recife (PB), Brazil. 10.Universidade Federal de Juiz de Fora, Juiz de Fora (MG), Brazil. 11.Universidade Federal de Minas Gerais, Belo Horizonte (MG), Brazil. 12.Hospital Geral de Fortaleza, Fortaleza (CE), Brazil. 13 Hospital Universitário Evangélico Mackenzie, Curitiba (PR), Brazil. 14.Universidade do Estado do Rio de Janeiro, Rio de Janeiro (RJ), Brazil. 15.Universidade Federal do Paraná, Curitiba (PR), Brazil. 16.Universidade Federal de São Paulo, São Paulo (SP), Brazil. 17.Pontifícia Universidade Católica, Campinas (SP), Brazil. 18.Universidade Federal do Espírito Santo, Vitória (ES), Brazil. 19.Irmandade da Santa Casa de Misericórdia de São Paulo, São Paulo (SP), Brazil.

*Corresponding author: samuel.ebd@gmail.com

\section{BACKGROUND}

Considering the difficulties to perform the coronavirus disease 2019 (COVID-19) diagnosis in Brazil, related to lack of resources for a massive testing, the social isolation was chosen as suitable strategy to mitigate the community transmission of severe acute respiratory syndrome coronavirus 2 (SARS-CoV-2) infection. The aim of the study was to describe the self-reported symptoms and how the COVID-19 diagnosis was performed in medical students who were participating of Mário Pinotti II (MPII) study compared to other medical students not involved in this voluntary activity.

\section{MATERIALS AND METHODS}

A web-based survey was carried out to perform a cross-sectional assessment and the data were collected using a Google Forms platform, after consent from the participants and released by email and/or WhatsApp message, from July 20th to August31st, 2020. The questionnaire included demographic data, participants' reporting symptoms and/or diagnosis of COVID-19, including information on their households, as well worries on themselves or their household contacts getting sick or die. The Brazilian Ministry of Health (BMH) criteria were used to define lab or epidemiological COVID-19 diagnosis. The clinically confirmed COVID-19 criterion was not used.

\section{RESULTS}

A total of 684 medical students age 18 to 39 years (median = 23 years) were enrolled in this study. Most of them were female (63\%) and single marital status (97\%). During the pandemic, $84 \%$ were living with their families. One-hundred thirty-eight (20\%) of them had self-reported flu symptoms and 154 had epidemiological household contact with confirmed uncomplicated COVID-19. Considering the symptomatic cases, the viral transmission way was: household (48\%), community (42\%) and into the hospital (10\%). Sixty-three (9.2\%) medical students were diagnosed as positive COVID-19, according to the BMH criteria. Most of them (81\%) became apprehensive concerning risk of transmission for their parents and siblings or worries about moderate-severe forms (88\%).

\section{CONCLUSIONS}

Our data showed high frequency of flu symptoms in medical students but with low frequency of testing. Although being young people, they had high awareness about risks of the disease and transmission, according to the epidemiological scenario. 